\title{
An Application of Multi Criteria Decision Making: Ranking of School Success
}

\author{
Mehmet Çitil*, Feride Tuğrul, Beyhan Yılmaz \\ Department of Mathematics, Kahramanmaraş Sütcü İmam University, Kahramanmaraş, Turkey \\ *citil@ksu.edu.tr
}

Received: 09 July 2018

Accepted: 07 February 2019

DOI: $10.18466 /$ cbayarfbe. 442031

\begin{abstract}
Decision making is the action of choosing between two or more options. Multicriteria decision making is a well-known concept that aims to select the best solution among several alternatives in decision making. For this paper have been benefitted from similarity measure for intuitionistic fuzzy sets in multi criteria decision making problem. This application is a method that gives very important and rational results in decision making. In this paper; success ranking of schools has been researched in multi criteria decision making. The aim of this study is to propose an application multi criteria decision making in intuitionistic fuzzy sets. Also from year to year ranking of school success has been determined with multi criteria decision making. Annual change of success of each school has been investigated. This paper is the first research that evaluates with application and offers suggestions in education. This application has been implemented for the first time in Turkey to achieve more consistent and better results. This study is not an educational research, only is an application made in the field of intuitionistic fuzzy logic.
\end{abstract}

Keywords: Intuitionistic fuzzy sets, similarity measure, decision making, multi criteria.

\section{Introduction}

The notion of fuzzy logic was firstly defined by Zadeh in 1965 [1]. Then, intuitionistic fuzzy sets (shortly IFS) were defined by Atanassov in 1986 [2]. Intuitionistic fuzzy sets form a generalization of the notion of fuzzy sets. The intuitionistic fuzzy set theory is useful in various application areas, such as algebraic structures, robotics, control systems, agriculture areas, computer, irrigation, economy and various engineering fields. Various applications of intuitionistic fuzzy set have been carried out through distance measures approach. Many researchers have explored various applications of intuitionistic fuzzy set such as medical diagnosis, medical application, career determination, real life situations, education, artificial intelligence, and networking.

Decision making is the action of choosing between two or more options. Multicriteria decision making is a wellknown concept that aims to select the best solution among several alternatives in decision making. The basic working principle of any MCDM method is same: Selection of Criteria, Selection of Alternatives, Selection of Aggregation Methods and ultimately Selection of Alternatives based on weights or outranking [3]. Some of the multi criteria decision making methods are as follows: Analytical Hierarchy Process (AHP), Fuzzy Multi Criteria Decision Making Process, ELECTRE Method, Preference Ranking Organization Method for Enrichment of Evaluations,
The TOPSIS Method. Fuzzy set theory offers a possibility for evaluating data involving the subjective features of human nature in the decision making process. Bellman and Zadeh the firstly introduced decision making in a fuzzy environment. Kickert pointed out that the multicriteria decision making problem is a kind of problem that all the alternatives in the choice set can be evaluated according to a number of criteria; he also pointed out that the problem is to construct an evaluation procedure to rank the set of alternatives in order of preference [4]. Multi criteria fuzzy decision making has been one of the quickly growing area in recent years on account of its practicality. In multi criteria decision making problems, usually the best alternative is chosen from alternatives according to criteria. Applications of multi criteria decision making problem have increased in intuitionistic fuzzy set. Multi criteria decision making methods based on intuitionistic fuzzy sets were studied in Li, Lin, Yuan and Xia, Liu and Wang and $\mathrm{Xu}$ [5-11]. Szmidt et al. provided a solution to a multicriteria decision making problem by using similarity measures for IFSs [5]. Later, Szmidt et al. proposed a new method of IFSs which takes into account not only the amount of information related to an alternative (expressed by a distance from an ideal positive alternative) but also the reliability of information represented by an alternative meant as how sure the information is and Szmidt et al. presented some of the extended decision making are presented. Many researcher have introduced this field: 
Liu, Wang, Chen, Ye, Zhang, Xu, etc.

In this paper, we have introduced an application of multi criteria decision making in success ranking of middle school using similarity measures in intuitionistic fuzzy sets. For this paper; middle schools in Kahramanmaraş city in Turkey have been researched. Each middle school points has been calculated depending on student examination score (over 100 marks total). We have used intuitionistic fuzzy sets as a tool since it incorporates the membership degree (the marks of the questions that have been correctly answered by the student), the nonmembership degree (the marks of the questions that have been wrongly answered by the student) and the hesitation degree (the marks of the questions that are free from any answer). This research has utilized official data that were obtained from the Ministry of Education.

Many institutions make decisions based on a single criterion in the selection of staff. But a single criterion may not always give accurate results. This application could be used in situations that are not dependent on a single criterion. The options are middle schools in this paper. Criteria that determine the success of middle school are lessons. The middle school points have calculated by taking the average of the results of that year's examinations of the students in the school. The criteria in this study have been determined as the basic lessons in middle school. Middle school points have been determined as criteria. Each criterion represents a lesson. Lessons are Turkish, Mathematics, Science, Social, English, Religion. The aim of this paper is to determination success ranking of middle school according to these criteria. Also from year to year ranking of school success has been determined with multi criteria decision making. Annual change of success of each school has been investigated. Multi criteria decision making has many application areas. For this paper have been benefitted from similarity measures for intuitionistic fuzzy sets that proposed new solution by Szmidt and Kacprzyk [5]. This method takes into account not only ideal positive alternative but also ideal negative alternative. It is important that the best choice is how close to the positive ideal solution and how far away from the negative ideal solution.

\section{Materials and Methods}

In this section, basic concepts will be given.

Definition 1. [2] Let $X \neq$. An intuitionistic fuzzy set $A$ in $X$;

$A=\left\{\left\langle x, \mu_{A}(x), v_{A}(x)\right\rangle \mid x \in X\right\}$,

$\mu_{A}(x), v_{A}(x), \pi_{A}(x): X \rightarrow[0,1]$

defined membership degree, nonmembership degree and hesitation degree of the element $x \in X$ respectively. $\mu_{A}(x)+v_{A}(x)+\pi_{A}(x)=1$.
Definition 2. [6] $M$ be a set of options and $C$ be a set of criteria

$M=\left\{M_{1}, M_{2}, \ldots, M_{m}\right\}, C=\left\{C_{1}, C_{2}, \ldots, C_{n}\right\}$

where each option $M_{i}$ is defined with intuitionistic fuzzy set;

$M_{i}=\left\{\left(C_{1}, \mu_{i 1}, v_{i 1}\right),\left(C_{2}, \mu_{i 2}, v_{i 2}\right), \ldots,\left(C_{n}, \mu_{i n}, v_{i n}\right)\right\}$,

$i=1,2$, ..

where $\mu_{i j}$ indicates the degree to which option $M_{i}$ satisfies criterion $C_{j}, v_{i j}$ indicates the degree to which option $M_{i}$ does not satisfy criterion $C_{j}$. The options should satisfy the criteria $C_{j}, C_{k}, \ldots$, and $C_{p}$ or criterion $C_{s}$, i.e.:

$\left(C_{j}\right.$ and $C_{k}$ and,.., and $\left.C_{p}\right)$ or $C_{s}$ $A\left(\mu_{A}=1, v_{A}=0\right.$ and $\left.\pi_{A}=0\right)$ represents the ideal positive solution and $B\left(\mu_{B}=0, v_{B}=1\right.$ and $\left.\pi_{B}=0\right)$ represents the ideal negative solution. So, $A$ is a fully satified criterion and $B$ is a fully dissatisfied criterion.

Definition 3. [5]

$\operatorname{Sim}\left(C_{i}, A\right)=\frac{l_{I F S}\left(C_{i}, A\right)}{l_{I F S}\left(C_{i}, B\right)}$

$l_{I F S}\left(C_{i}, A\right)$ and $l_{I F S}\left(C_{i}, B\right)$ are defined as:

$$
l_{I F S}\left(C_{i}, A\right)=\frac{1}{2} \sum_{i=1}^{n}\left(\left|1-\mu_{C_{i}}\right|+\left|0-v_{C_{i}}\right|+\left|0-\pi_{C_{i}}\right|\right)
$$

$l_{I F S}\left(C_{i}, B\right)=\frac{1}{2} \sum_{i=1}^{n}\left(\left|0-\mu_{C_{i}}\right|+\left|1-v_{C_{i}}\right|+\left|0-\pi_{C_{i}}\right|\right)$

For, $0 \leq \operatorname{Sim}\left(C_{i}, A\right) \leq \infty$.

The problem of finding an option $M_{i}$ satisfying in the best way condition can be solved by evaluating each option $M_{i}$

$E\left(M_{i}\right.$

$\left.\left.\ldots, \operatorname{Sim}\left(A, C_{p}\right)\right], \operatorname{Sim}\left(A, C_{s}\right)\right\}$

Condition means that for each $M_{i}$ we look for the worst satisfied criterion $W_{i}$ among $C_{j}, C_{k}, \ldots$, and $C_{p}$ and next- we look for the better criterion between

$W_{i}$ and $C_{s}$. The worst means the least similar and the least similar and the best means the most similar.

The smallest value among $E\left(M_{i}\right), i=1, \ldots, m$ points 
out the option which best satisfies condition.

\section{Results and Discussion}

In this section; application of success ranking with similarity measure has been given.

$S=\left\{S_{1}, S_{2}, S_{3}, S_{4}, S_{5}, S_{6}, S_{7}, S_{8}, S_{9}, S_{10}\right\}$ be set of high high schools.

$L=\left\{L_{1}, L_{2}, L_{3}, L_{4}, L_{5}, L_{6}\right\}$ be set of criteria.

Set of criteria respectively are $L=\{$ Turkish, Mathematics, Science, Social, English, Religion $\}$ The criteria for middle schools are lessons. The points of schools in 2014, 2015, 2016, 2017 years in the tables below:

Table 1. The points of $S_{1}$ middle school.

\begin{tabular}{|c|c|c|c|c|}
\hline$S_{1}$ & 2014 & 2015 & 2016 & 2017 \\
\hline$L_{1}$ & $(0.461,0.486,0.053)$ & $(0.535,0.419,0.046)$ & $(0.519,0.433,0.048)$ & $(0.41,0.531,0.059)$ \\
\hline$L_{2}$ & $(0.311,0.621,0.068)$ & $(0.338,0.596,0.066)$ & $(0.317,0.615,0.068)$ & $(0.3,0.63,0.07)$ \\
\hline$L_{3}$ & $(0.42,0.522,0.058)$ & $(0.484,0.465,0.051)$ & $(0.502,0.449,0.049)$ & $(0.54,0.414,0.046)$ \\
\hline$L_{4}$ & $(0.448,0.497,0.055)$ & $(0.566,0.391,0.043)$ & $(0.512,0.44,0.048)$ & $(0.5,0.45,0.05)$ \\
\hline$L_{5}$ & $(0.374,0.564,0.062)$ & $(0.349,0.586,0.065)$ & $(0.488,0.461,0.051)$ & $(0.38,0.558,0.062)$ \\
\hline$L_{6}$ & $(0.509,0.442,0.049)$ & $(0.762,0.785,0.023)$ & $(0.685,0.284,0.031)$ & $(0.54,0.414,0.046)$ \\
\hline
\end{tabular}

From Definition 3; calculations for each school are as follows:

Table 2. Calculations for $S_{1}$

\begin{tabular}{|l|l|l|}
\hline$S_{1}$ & 2014 & $\mathrm{E}\left(S_{1}\right)=0.879$ \\
\hline & 2015 & $\mathrm{E}\left(S_{1}\right)=0.956$ \\
\hline & 2016 & $\mathrm{E}\left(S_{1}\right)=0.439$ \\
\hline & 2017 & $\mathrm{E}\left(S_{1}\right)=0.784$ \\
\hline
\end{tabular}

Table 3. The points of $S_{2}$ middle school

\begin{tabular}{|c|c|c|c|c|}
\hline$S_{2}$ & 2014 & 2015 & 2016 & 2017 \\
\hline$L_{1}$ & $(0.979,0.019,0.002)$ & $(0.929,0.064,0.007)$ & $(0.93,0.063,0.007)$ & $(0.87,0.117,0.013)$ \\
\hline$L_{2}$ & $(0.915,0.077,0.008)$ & $(0.871,0.119,0.01)$ & $(0.948,0.047,0.005)$ & $(0.89,0.099,0.011)$ \\
\hline$L_{3}$ & $(0.908,0.083,0.009)$ & $(0.931,0.063,0.006)$ & $(0.941,0.054,0.005)$ & $(0.98,0.018,0.002)$ \\
\hline$L_{4}$ & $(0.922,0.071,0.007)$ & $(0.907,0.084,0.009)$ & $(0.932,0.062,0.006)$ & $(0.95,0.045,0.005)$ \\
\hline$L_{5}$ & $(0.895,0.095,0.01)$ & $(0.861,0.126,0.013)$ & $(0.938,0.056,0.006)$ & $(0.97,0.027,0.003)$ \\
\hline$L_{6}$ & $(0.901,0.09,0.009)$ & $(0.971,0.027,0.002)$ & $(0.973,0.025,0.002)$ & $(0.95,0.045,0.005)$ \\
\hline
\end{tabular}

Table 4. Calculations for $S_{2}$

\begin{tabular}{|l|l|l|}
\hline$S_{2}$ & 2014 & $\mathrm{E}\left(S_{2}\right)=0.108$ \\
\hline & 2015 & $\mathrm{E}\left(S_{2}\right)=0.029$ \\
\hline & 2016 & $\mathrm{E}\left(S_{2}\right)=0.027$ \\
\hline & 2017 & $\mathrm{E}\left(S_{2}\right)=0.052$ \\
\hline
\end{tabular}

Table 5. The points of $S_{3}$ middle school

\begin{tabular}{|c|c|c|c|c|}
\hline$S_{3}$ & 2014 & 2015 & 2016 & 2017 \\
\hline$L_{1}$ & $(0.739,0.241,0.02)$ & $(0.72,0.252,0.028)$ & $(0.673,0.295,0.032)$ & $(0.752,0.223,0.02)$ \\
\hline$L_{2}$ & $(0.509,0.442,0.049)$ & $(0.488,0.461,0.051)$ & $(0.489,0.46,0.051)$ & $(0.559,0.396,0.04)$ \\
\hline$L_{3}$ & $(0.608,0.353,0.039)$ & $(0.628,0.665,0.037)$ & $(0.651,0.315,0.034)$ & $(0.65,0.315,0.035)$ \\
\hline$L_{4}$ & $(0.653,0.313,0.034)$ & $(0.658,0.308,0.034)$ & $(0.646,0.319,0.035)$ & $(0.745,0.229,0.02)$ \\
\hline$L_{5}$ & $(0.493,0.457,0.05)$ & $(0.482,0.467,0.051)$ & $(0.608,0.353,0.039)$ & $(0.636,0.327,0.03)$ \\
\hline$L_{6}$ & $(0.732,0.242,0.026)$ & $(0.873,0.115,0.012)$ & $(0.818,0.164,0.018)$ & $(0.805,0.175,0.01)$ \\
\hline
\end{tabular}


Table 6. Calculations for $S_{3}$

\begin{tabular}{|l|l|l|}
\hline$S_{3}$ & 2014 & $\mathrm{E}\left(S_{3}\right)=0.353$ \\
\hline & 2015 & $\mathrm{E}\left(S_{3}\right)=0.143$ \\
\hline & 2016 & $\mathrm{E}\left(S_{3}\right)=0.217$ \\
\hline & 2017 & $\mathrm{E}\left(S_{3}\right)=0.236$ \\
\hline
\end{tabular}

Table 7. The points of $S_{4}$ middle school

\begin{tabular}{|c|c|c|c|c|}
\hline$S_{4}$ & 2014 & 2015 & 2016 & 2017 \\
\hline$L_{1}$ & $(0.788,0.191,0.021)$ & $(0.768,0.209,0.023)$ & $(0.736,0.238,0.026)$ & $(0.69,0.279,0.031)$ \\
\hline$L_{2}$ & $(0.59,0.369,0.041)$ & $(0.546,0.409,0.045)$ & $(0.608,0.353,0.039)$ & $(0.67,0.297,0.033)$ \\
\hline$L_{3}$ & $(0.682,0.287,0.031)$ & $(0.698,0.272,0.03)$ & $(0.711,0.261,0.028)$ & $(0.83,0.153,0.017)$ \\
\hline$L_{4}$ & $(0.722,0.251,0.027)$ & $(0.728,0.245,0.027)$ & $(0.737,0.237,0.026)$ & $(0.77,0.207,0.023)$ \\
\hline$L_{5}$ & $(0.544,0.411,0.045)$ & $(0.552,0.404,0.044)$ & $(0.688,0.281,0.031)$ & $(0.68,0.288,0.032)$ \\
\hline$L_{6}$ & $(0.756,0.22,0.024)$ & $(0.881,0.108,0.011)$ & $(0.875,0.113,0.012)$ & $(0.82,0.162,0.018)$ \\
\hline
\end{tabular}

Table 8. Calculations for $S_{4}$

\begin{tabular}{|c|c|c|}
\hline$S_{4}$ & 2014 & $\mathrm{E}\left(S_{4}\right)=0.312$ \\
\hline & 2015 & $\mathrm{E}\left(S_{4}\right)=0.133$ \\
\hline & 2016 & $\mathrm{E}\left(S_{4}\right)=0.14$ \\
\hline & 2017 & $\mathrm{E}\left(S_{4}\right)=0.214$ \\
\hline
\end{tabular}

Table 9. The points of $S_{5}$ middle school

\begin{tabular}{|c|c|c|c|c|}
\hline$S_{5}$ & 2014 & 2015 & 2016 & 2017 \\
\hline$L_{1}$ & $(0.717,0.255,0.028)$ & $(0.711,0.261,0.028)$ & $(0.71,0.261,0.029)$ & $(0.81,0.171,0.019)$ \\
\hline$L_{2}$ & $(0.47,0.477,0.053)$ & $(0.494,0.456,0.05)$ & $(0.522,0.431,0.047)$ & $(0.63,0.333,0.037)$ \\
\hline$L_{3}$ & $(0.591,0.369,0.04)$ & $(0.615,0.347,0.038)$ & $(0.682,0.287,0.031)$ & $(0.74,0.234,0.026)$ \\
\hline$L_{4}$ & $(0.623,0.34,0.037)$ & $(0.677,0.291,0.032)$ & $(0.682,0.287,0.031)$ & $(0.65,0.315,0.035)$ \\
\hline$L_{5}$ & $(0.469,0.478,0.053)$ & $(0.502,0.449,0.049)$ & $(0.662,0.305,0.033)$ & $(0.79,0.189,0.021)$ \\
\hline$L_{6}$ & $(0.728,0.245,0.027)$ & $(0.854,0.132,0.014)$ & $(0.85,0.135,0.015)$ & $(0.88,0.108,0.012)$ \\
\hline
\end{tabular}

Table 10. Calculations for $S_{5}$

\begin{tabular}{|c|c|c|}
\hline$S_{5}$ & 2014 & $\mathrm{E}\left(S_{5}\right)=0.36$ \\
\hline & 2015 & $\mathrm{E}\left(S_{5}\right)=0.168$ \\
\hline & 2016 & $\mathrm{E}\left(S_{5}\right)=0.173$ \\
\hline & 2017 & $\mathrm{E}\left(S_{5}\right)=0.134$ \\
\hline
\end{tabular}

Table 11. The points of $S_{6}$ middle school

\begin{tabular}{|c|c|c|c|c|}
\hline$S_{6}$ & 2014 & 2015 & 2016 & 2017 \\
\hline$L_{1}$ & $(0.603,0.358,0.039)$ & $(0.583,0.376,0.041)$ & $(0.603,0.358,0.039)$ & $(0.5,0.45,0.05)$ \\
\hline$L_{2}$ & $(0.342,0.593,0.065)$ & $(0.328,0.605,0.067)$ & $(0.406,0.535,0.059)$ & $(0.4,0.54,0.06)$ \\
\hline$L_{3}$ & $(0.482,0.467,0.051)$ & $(0.517,0.435,0.048)$ & $(0.528,0.425,0.047)$ & $(0.6,0.36,0.04)$ \\
\hline$L_{4}$ & $(0.528,0.425,0.047)$ & $(0.566,0.391,0.043)$ & $(0.671,0.297,0.032)$ & $(0.55,0.405,0.045)$ \\
\hline$L_{5}$ & $(0.464,0.483,0.053)$ & $(0.403,0.538,0.059)$ & $(0.553,0.403,0.044)$ & $(0.5,0.45,0.05)$ \\
\hline$L_{6}$ & $(0.603,0.358,0.039)$ & $(0.739,0.235,0.026)$ & $(0.837,0.147,0.016)$ & $(0.71,0.261,0.029)$ \\
\hline
\end{tabular}

Table 12. Calculations for $S_{6}$

\begin{tabular}{|l|l|l|}
\hline$S_{6}$ & 2014 & $\mathrm{E}\left(S_{6}\right)=0.618$ \\
\hline & 2015 & $\mathrm{E}\left(S_{6}\right)=0.341$ \\
\hline & 2016 & $\mathrm{E}\left(S_{6}\right)=0.191$ \\
\hline & 2017 & $\mathrm{E}\left(S_{6}\right)=0.392$ \\
\hline
\end{tabular}

Table 13. The points of $S_{7}$ middle school.

\begin{tabular}{|c|c|c|c|c|}
\hline$S_{7}$ & 2014 & 2015 & 2016 & 2017 \\
\hline$L_{1}$ & $(0.539,0.415,0.046)$ & $(0.55,0.405,0.045)$ & $(0.51,0.441,0.049)$ & $(0.49,0.459,0.051)$ \\
\hline$L_{2}$ & $(0.36,0.576,0.064)$ & $(0.336,0.598,0.066)$ & $(0.367,0.57,0.063)$ & $(0.46,0.486,0.054)$ \\
\hline$L_{3}$ & $(0.481,0.468,0.051)$ & $(0.487,0.462,0.051)$ & $(0.529,0.424,0.047)$ & $(0.65,0.315,0.035)$ \\
\hline$L_{4}$ & $(0.464,0.483,0.053)$ & $(0.498,0.452,0.05)$ & $(0.493,0.457,0.05)$ & $(0.59,0.369,0.041)$ \\
\hline
\end{tabular}




\begin{tabular}{|l|l|l|l|l|}
\hline$L_{5}$ & $(0.368,0.569,0.063)$ & $(0.365,0.572,0.063)$ & $(0.485,0.464,0.051)$ & $(0.45,0.495,0.055)$ \\
\hline$L_{6}$ & $(0.609,0.352,0.039)$ & $(0.736,0.238,0.026)$ & $(0.707,0.264,0.029)$ & $(0.69,0.279,0.031)$ \\
\hline
\end{tabular}

Table 14. Calculations for $S_{7}$

\begin{tabular}{|l|l|l|}
\hline$S_{7}$ & 2014 & $\mathrm{E}\left(S_{7}\right)=0.603$ \\
\hline & 2015 & $\mathrm{E}\left(S_{7}\right)=0.346$ \\
\hline & 2016 & $\mathrm{E}\left(S_{7}\right)=0.398$ \\
\hline & 2017 & $\mathrm{E}\left(S_{7}\right)=0.429$ \\
\hline
\end{tabular}

Table 15. The points of $S_{8}$ middle school

\begin{tabular}{|c|c|c|c|c|}
\hline$S_{8}$ & 2014 & 2015 & 2016 & 2017 \\
\hline$L_{1}$ & $(0.56,0.396,0.044)$ & $(0.552,0.404,0.044)$ & $(0.521,0.432,0.047)$ & $(0.49,0.459,0.051)$ \\
\hline$L_{2}$ & $(0.355,0.581,0.064)$ & $(0.314,0.618,0.068)$ & $(0.337,0.597,0.066)$ & $(0.45,0.505,0.055)$ \\
\hline$L_{3}$ & $(0.479,0.469,0.052)$ & $(0.512,0.44,0.048)$ & $(0.52,0.432,0.048)$ & $(0.69,0.279,0.031)$ \\
\hline$L_{4}$ & $(0.526,0.427,0.047)$ & $(0.503,0.448,0.049)$ & $(0.499,0.451,0.05)$ & $(0.52,0.432,0.048)$ \\
\hline$L_{5}$ & $(0.368,0.569,0.063)$ & $(0.36,0.576,0.064)$ & $(0.409,0.532,0.059)$ & $(0.46,0.486,0.054)$ \\
\hline$L_{6}$ & $(0.6,0.36,0.04)$ & $(0.714,0.258,0.028)$ & $(0.709,0.262,0.029)$ & $(0.66,0.306,0.034)$ \\
\hline
\end{tabular}

Table 16. Calculations for $S_{8}$

\begin{tabular}{|l|l|l|}
\hline$S_{8}$ & 2014 & $\mathrm{E}\left(S_{8}\right)=0.625$ \\
\hline & 2015 & $\mathrm{E}\left(S_{8}\right)=0.385$ \\
\hline & 2016 & $\mathrm{E}\left(S_{8}\right)=0.394$ \\
\hline & 2017 & $\mathrm{E}\left(S_{8}\right)=0.489$ \\
\hline
\end{tabular}

Table 17. The points of $S_{9}$ middle school

\begin{tabular}{|c|c|c|c|c|}
\hline$S_{9}$ & 2014 & 2015 & 2016 & 2017 \\
\hline$L_{1}$ & $(0.375,0.563,0.062)$ & $(0.524,0.429,0.047)$ & $(0.341,0.594,0.065)$ & $(0.41,0.531,0.059)$ \\
\hline$L_{2}$ & $(0.278,0.65,0.072)$ & $(0.261,0.666,0.073)$ & $(0.25,0.675,0.075)$ & $(0.38,0.558,0.062)$ \\
\hline$L_{3}$ & $(0.393,0.547,0.06)$ & $(0.432,0.512,0.056)$ & $(0.426,0.517,0.057)$ & $(0.5,0.45,0.05)$ \\
\hline$L_{4}$ & $(0.403,0.538,0.059)$ & $(0.422,0.521,0.057)$ & $(0.343,0.592,0.065)$ & $(0.5,0.45,0.05)$ \\
\hline$L_{5}$ & $(0.334,0.6,0.066)$ & $(0.323,0.61,0.067)$ & $(0.33,0.603,0.067)$ & $(0.32,0.612,0.068)$ \\
\hline$L_{6}$ & $(0.518,0.434,0.048)$ & $(0.657,0.309,0.034)$ & $(0.528,0.425,0.047)$ & $(0.59,0.369,0.041)$ \\
\hline
\end{tabular}

Table 18. Calculations for $S_{9}$

\begin{tabular}{|c|c|c|}
\hline$S_{9}$ & 2014 & $\mathrm{E}\left(S_{9}\right)=0.851$ \\
\hline & 2015 & $\mathrm{E}\left(S_{9}\right)=0.496$ \\
\hline & 2016 & $\mathrm{E}\left(S_{9}\right)=0.82$ \\
\hline & 2017 & $\mathrm{E}\left(S_{9}\right)=0.649$ \\
\hline
\end{tabular}

Table 19. The points of $S_{10}$ middle school

\begin{tabular}{|c|c|c|c|c|}
\hline$S_{10}$ & 2014 & 2015 & 2016 & 2017 \\
\hline$L_{1}$ & $(0.427,0.516,0.057)$ & $(0.392,0.548,0.06)$ & $(0.297,0.633,0.07)$ & $(0.27,0.657,0.073)$ \\
\hline$L_{2}$ & $(0.336,0.598,0.066)$ & $(0.21,0.711,0.079)$ & $(0.226,0.697,0.077)$ & $(0.25,0.675,0.075)$ \\
\hline$L_{3}$ & $(0.413,0.529,0.058)$ & $(0.322,0.611,0.067)$ & $(0.415,0.527,0.058)$ & $(0.41,0.531,0.059)$ \\
\hline$L_{4}$ & $(0.329,0.604,0.067)$ & $(0.309,0.622,0.069)$ & $(0.365,0.572,0.063)$ & $(0.5,0.45,0.05)$ \\
\hline$L_{5}$ & $(0.313,0.619,0.068)$ & $(0.268,0.659,0.073)$ & $(0.287,0.642,0.071)$ & $(0.29,0.639,0.071)$ \\
\hline$L_{6}$ & $(0.501,0.444,0.055)$ & $(0.663,0.304,0.033)$ & $(0.53,0.423,0.047)$ & $(0.549,0.39,0.061)$ \\
\hline
\end{tabular}

Table 20. Calculations for $S_{10}$

\begin{tabular}{|l|l|l|}
\hline$S_{10}$ & 2014 & $\mathrm{E}\left(S_{10}\right)=0.897$ \\
\hline & 2015 & $\mathrm{E}\left(S_{10}\right)=0.484$ \\
\hline & 2016 & $\mathrm{E}\left(S_{10}\right)=0.814$ \\
\hline & 2017 & $\mathrm{E}\left(S_{10}\right)=0.739$ \\
\hline
\end{tabular}

The smallest value among $E\left(M_{i}\right)$ points out the option which best satisfies condition. According to the above calculations, each school's from year to year ranking of school success is as follows: For $\quad S_{1}: \quad 2016_{S_{1}}, 2017_{S_{1}}, 2014_{S_{1}}, 2015_{S_{1}}$ For $\quad S_{2}: 2016_{S_{2}}, 2015_{S_{2}}, 2017_{S_{2}}, 2014_{S_{2}}$ 


$\begin{array}{llll}\text { For } & S_{3}: & 2015_{S_{3}}, 2016_{S_{3}}, 2017_{S_{3}}, 2014_{S_{3}} \\ \text { For } & S_{4}: & 2015_{S_{4}}, 2016_{S_{4}}, 2017_{S_{4}}, 2014_{S_{4}} \\ \text { For } & S_{5}: & 2017_{S_{5}}, 2015_{S_{5}}, 2016_{S_{5}}, 2014_{S_{5}} \\ \text { For } & S_{6}: & 2016_{S_{6}}, 2015_{S_{6}}, 2017_{S_{6}}, 2014_{S_{6}} \\ \text { For } & S_{7}: & 2015_{S_{7}}, 2016_{S_{7}}, 2017_{S_{7}}, 2014_{S_{7}} \\ \text { For } & S_{8}: & 2015_{S_{8}}, 2016_{S_{8}}, 2017_{S_{8}}, 2014_{S_{8}} \\ \text { For } & S_{9} & : & 2015_{S_{9}}, 2017_{S_{9}}, 2016_{S_{9}}, 2014_{S_{9}}\end{array}$

For $S_{10}: 2015_{S_{10}}, 2017_{S_{10}}, 2016_{S_{10}}, 2014_{S_{10}}$

According to the above calculations, for each year ranking of school success is as follows:

For $2014: S_{2}, S_{4}, S_{3}, S_{5}, S_{7}, S_{6}, S_{8}, S_{9}, S_{1}, S_{10}$

For $\quad 2015: \quad S_{2}, S_{4}, S_{3}, S_{5}, S_{6}, S_{7}, S_{8}, S_{10}, S_{9}, S_{1}$

For $\quad 2016: \quad S_{2}, S_{4}, S_{5}, S_{6}, S_{3}, S_{8}, S_{7}, S_{1}, S_{10}, S_{9}$

For $2017: S_{2}, S_{5}, S_{4}, S_{3}, S_{6}, S_{7}, S_{8}, S_{9}, S_{10}, S_{1}$

In this paper; each year ranking of school success and each school's from year to year ranking of school success have been made separately. For each year ranking of school success has been varied. This situation has different causes: student change at school, teacher change at school, difficulty or simplicity of examination, socio-economic status and psychology of students.

This method could be used to determine the success of each lesson. If these application results are taken into consideration; the success of the student, the success of teacher and success of school will increase. This method is suitable in order to achieve more sensible results. Applications could be made in different areas with this method. Many institutions make decisions based on a single criterion in the selection of staff. But a single criterion may not always give accurate results. This application could be used in all situations that are not dependent on a single criterion.

\section{Author's Contributions}

Mehmet Çitil: This author is mainly responsible for this manuscript. Created the manuscript in scientific and theoretical terms. Prepared the application and interpretation section.

Feride Tuğrul: Made the numerical calculations in the manuscript. Prepared the general outline of the manuscript.

Beyhan Yilmaz: Assisted in numerical calculations, result interpretation and helped in manuscript preparation.

\section{Ethics}

There are no ethical issues after the publication of this manuscript.

\section{References}

1. Zadeh, L, A, 1965. Fuzzy Sets. Information and Control; 8: $338-$ 353.

\section{Conclusion}

For this paper have been benefitted from similarity measures for intuitionistic fuzzy sets that proposed new solution by Szmidt and Kacprzyk [5]. The advantage of this method; this method takes into account not only ideal positive alternative but also ideal negative alternative. It is important that the best choice is how close to the positive ideal solution and how far away from the negative ideal solution. In this paper; from year to year ranking of school success has been determined with multi criteria decision making. Annual change of success of each school has been investigated. For this paper have been benefitted from similarity measure for intuitionistic fuzzy sets in multi criteria decision making problem. In this paper; each year ranking of school success and each school's from year to year ranking of school success have been made separately. This application is a method that gives very important and rational results in decision making, in education. This article is the first article that evaluates with application and offers suggestions in education. This application has been implemented for the first time in Turkey to achieve more consistent and better results. Using this method, the success of school could be observed every year.

2. Atanassov, K, 1986. Intuitionistic fuzzy set. Fuzzy Sets and Systems; 20(1): 87-96.

3. Majumder, M, 2015. Multi Criteria Decision Making, Springer; 2: $35-47$.

4. Kickert, W, J, M, Fuzzy Theories on Decision Making: A Critical Review, Kluwer, Boston, 1978.

5. Szmidt, E, Kacprzyk, J, 2006. An Application of Intuitionistic Fuzzy Set Similarity Measures to a Multi-criteria Decision Making Problem. Springer-Verlag Heidelberg; 314-323.

6. Chen, S, Tan, J, 1994. Handling Multicriteria Fuzzy DecisionMaking Problems Based On Vague Set Theory. Fuzzy Sets and Systems; 67: 163-172.

7. Atanassov, K, Intuitionistic Fuzzy Sets, Theory and Applications, Physica-Verlag Heidelberg, Germany, 1999; pp 319.

8. Szmidt, E, Kacprzyk, J, 2000. Distances between Intuitionistic Fuzzy Sets, Fuzzy Sets and Systems; 114(3): 505-518.

9. Yen, J, 2007. Improved Method of Multicriteria Fuzzy DecisionMaking Based on Vague Sets. Computer-Aided Design; 39: 164169

10. Nayagam, V, Muralikrishnan, S, Sivaraman, G, 2011. Multicriteria Decision-Making Method Based on Interval-valued Intuitionistic Fuzzy Sets. Expert Systems with Applications; 38: 1464-1467.

11. Bangui, H, Ge, M, Buhnova, B, Rakrak, S, Raghay, S, Pitner, T, 2017. Multi-Criteria Decision Analysis Methods in the Mobile Cloud Offloading Paradigm, Journal of Sensor and Actuator Networks; 6(4): 25. 